\title{
Bacteriological Analysis of Escalator Handrails and Lift Buttons of Selected Shopping Malls in Lusaka Zambia: The Public Health Risk Implication
}

\author{
Kapunda Masuwa ${ }^{1}$, Annie Kalonda ${ }^{1}$, Sydney Malama ${ }^{2 *}$, Henry, Mwelwa Chimana ${ }^{1}$ \\ ${ }^{1}$ University of Zambia, School of Health Sciences, Department of Biomedical Sciences, Zambia \\ ${ }^{2}$ Univeristy of Zambia, School of Natural Sciences, Department of Biological Sciences, Zambia \\ *Corresponding Author: Sydney Malama, University of Zambia, School of Natural Sciences, Department \\ of Biological Sciences, Zambia
}

\begin{abstract}
Many environmental materials play a role in the spread of pathogens and infectious diseases. Studies from around the world have shown that surfaces of public places like shopping malls are usually contaminated and play a role in the increasing incidences of outbreaks of certain diseases. However, there is little attention on the issue of bacterial contamination of escalator handrails and lift buttons in Zambia.

The main objective of this study was to assess the bacterial contamination of escalator handrails and lift buttons in selected shopping malls of Lusaka urban.

This was a descriptive cross-sectional study with a sample simple size of 32. It was completed in May, 2017. The samples were cultured and identified using Gram staining, colony morphology and biochemicals. Antimicrobial susceptibility testing was done using the Kirby-Bauer Disc Diffusion method.

All of the 32 samples collected samples yielded bacteria. A total of 52 bacteria were isolated as follows; E. coli 30 (57.7\%), coagulase negative Staphylococcus 12 (23.1\%), Bacillus species 8 (15.4\%), Proteus species 1 (1.9\%) and Pseudomonas species $1(1.9 \%)$. All the isolates were resistant to ampicillin. E. coli and Pseudomonas species were resistant to cefotaxime, and Proteus species were resistant to cotrimoxazole.

These results suggest that escalator handrails and lift buttons may play a role in transmission of drug resistant bacteria therefore, creating a public health risk. Hence, there is need of improving hygiene practices and regulating the use of antibiotics.
\end{abstract}

\section{INTRODUCTION}

Many environmental materials serve as a mode of spread of pathogens in the population in many ways. Hence, the environment plays an important role in the transmission of microbial agents to humans (Anderson, 1991). The most common media of microbial transmission are water, soil, air and certain objects such door handles among others (Elsergany et al., 2015). People may also serve as medium of transmission through physical contact with each other or indirect contact with contaminated surfaces (Elsergany et al., 2015). In addition, some enteric and respiratory pathogens are capable of surviving for several hours to months on fomites depending on their number, type and the environment (Lopez et al., 2013). The contamination of different objects by potential pathogenic microorganisms is of public health importance, as such, contaminated materials can be a possible sources of transmission of such pathogens (Neel, 2012). This is because, communicable diseases may be spread through contact with these contaminated fomites (Alwakeel and Nasser, 2011).

A shopping mall is a large enclosed business centre, often two to three or more stories high. It has numerous stores, entertainment facilities such as movie theatres, fast-food outlets, restaurants, pubs and public places (Dictionary of architecture, 1952). People from all walks of life, different cultures, age, students, health personnel, and the general public visit shopping malls for business, entertainment and refreshment. Fomites in such a public place could serve as a reservoir and source of infection via indirect contact (Lopez et al., 2013).This could be through hand-to-mouth, hand-to-eye, hand to nose or by direct means, from surface to mouth (Lopez et al., 2013). In case an individual is a carrier of a pathogen that may be transmitted through indirect contact, there is a possibility of these pathogens being transmitted to others by contaminating surfaces like escalator handrails and lift buttons (Elsergany et al., 2015). 
Many instruments and objects in the clinical environments are contaminated with bacteria that cause nosocomial infections which serve as potential environmental reservoir and source of bacterial crosscontamination between individuals and patients who come into direct contact with these devices (Brady et al., 2009). Such objects may include mobile phones for health personnel who might visit a shopping mall with the contaminated gadget and touch the escalator handrails. Bacteria like Listeria monocytogenes is capable of surviving for longer period on surfaces (Wilks et al., 2006). Surfaces of public restrooms like those at shopping malls may harbour pathogenic bacteria which have longer survival rate (Flores et al., 2011). These bacteria can be on taps hence exposing hands to contamination, which may further touch escalator handrails or lift buttons exposing other escalator and lift users to infection (Mkrtchyan et al., 2013). Staphylococcaceae are some of the most common bacteria found in restrooms (Mkrtchyan et al., 2013)

The spreading of outbreaks might be due to contamination of surfaces of critical areas in public places like shopping malls. A chronic carrier from a typhoid endemic area may visit a shopping mall with contaminated hands and touch escalator handrails or lift button, exposing others to pathogenic bacteria and hence further spread the infection. Therefore, the aim of this study is to assess the bacterial contamination of escalator handrails and lift buttons in selected shopping malls of Lusaka.

\section{MATERials AND MethodS}

This was a descriptive cross-sectional study in which a total of 32 samples were collected from six malls coded; Mall A, Mall B, Mall C, Mall D, Mall E and Mall F.

\subsection{Sample Collection from Escalator Handrails and Lift Buttons}

Samples were collected, in the morning, at noon and in the evening by swabbing the surfaces of escalator handrails and lift buttons with Amies agar gel medium transport swabs. The Amies agar gel medium transport swabs were taken to the laboratory for culturing within an hour or two of collection. All the samples were cultured within 24 hours of collection.

\subsection{Detection of Bacterial Isolates from Escalator Handrails and Lift Buttons}

The collected samples were first inoculated in trypton nutrient broth for $18-24 \mathrm{hrs}$ at $37^{\circ} \mathrm{C}$. After which they were sub-cultured on blood agar, MacConkey and chocolate agar by streaking the swabs on the agar plates. Then the plates were be incubated at $37^{\circ} \mathrm{C}$ for 18 - $24 \mathrm{hrs}$, the blood agar and chocolate agar plate were incubated anaerobically. After 24 hours of incubation, the plates were examined for bacterial growth. The plates with bacterial growth were further examined macroscopically by observing the colony growth, colony morphology, and colony colour and purity. Smears of the isolates from each agar plate were made and stained using the Gram stain method. Then the Gram stained smears were examined microscopically to distinguish the morphology and between Gram positive and Gram negative bacteria.

Based on the Gram stain results and morphology of the isolated bacteria, biochemical identification of the bacteria were done. For Gram positive cocci isolates, catalase test was performed to differentiate Staphylococcus species from Streptococcus species. Then a coagulase test was performed to distinguish Staphylococcus aureus from the other Staphylococci. Enterobacteriaceae isolates were identified using Triple Iron Sugar Agar, Simmons Citrate, Urea and Indole tests.

\subsection{Determination of Antimicrobial Susceptibility Patterns}

The Kirby-Bauer Disc Diffusion method was used to determine the antimicrobial susceptibility patterns according to the Clinical and Laboratory Standards Institute (CLSI) guidelines. Well separated colonies were collected from each these cultures, using a non-toxic sterile swab. The separated colonies were suspended into 4 to $5 \mathrm{ml}$ of sterile physiological saline to obtain a $0.5 \mathrm{McF}$ arland density. These bacteria were further spread evenly on the Mueller Hinton agar plate, and then the antimicrobial discs were be gently pressed on the Mueller Hinton agar plate with sterile forceps ensuring that discs are not closer than $24 \mathrm{~mm}$ from centre to centre. The inoculated plates were incubated for 18 to 24 hours at $37^{\circ} \mathrm{C}$. After 18 to 24 hours, the zones of inhibition were measured using a measuring rule and end points determined based on the areas showing no bacterial growth visible to the naked eye . The results were interpreted as susceptible (S), intermediate (I) and resistant (R) based on the CLSI guidelines. Qquality control was performed by using reference strains E. coli ATCC 25922 and S. aureus ATCC 25923 according to CLSI guidelines.

Some of the antimicrobial agents that were tested include, gentamicin, ciprofloxacin, erythromycin, amoxicillin, ampicillin, chloramphenicol, cloxacillin, cefotaxime, penicillin, cefuroxime, oxacillin, and vancomycin. 


\section{RESULTS}

\subsection{Detection of Bacteria on Escalator Handrails and Lifts}

A total of 32 samples were collected from 6 different malls; 5 from each mall, except for Mall D were 7 samples were collected. The overall results showed that there was $100 \%$ bacterial contamination because every sample had a significant bacterial growth. From the 32 samples collected, a total of 52 bacteria were isolated. Of the 52 bacteria isolated 30 (57.7\%) were E.coli, 12 (23.1\%) coagulase negative Staphylococcus (CoNS), 8 (15.4\%) Bacillus species, 1 (1.9\%) Proteus species and 1 (1.9\%) Pseudomonas species as shown in Figure 4.1. Supplementary information on detection of bacteria from specific malls is in Appendix 7.1.

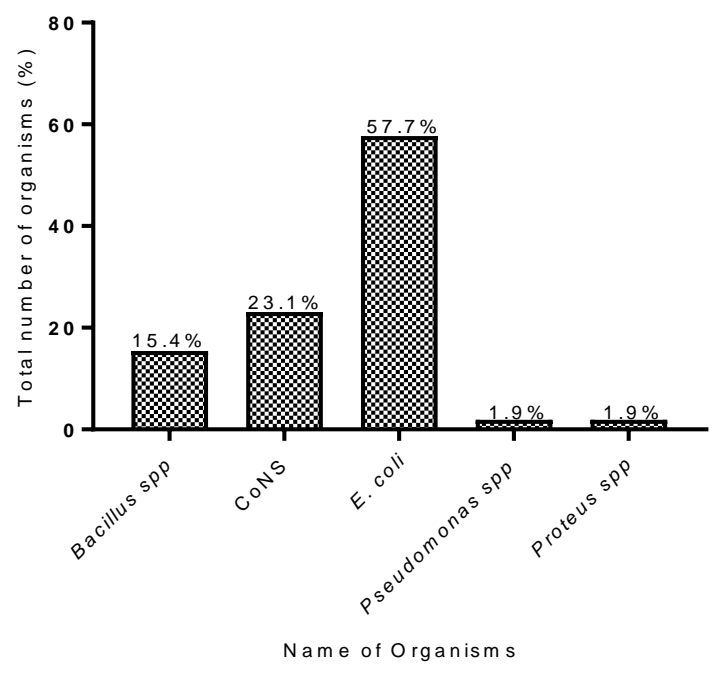

Figure4.1. Overall Frequency of Isolation of Bacteria from different shopping malls. CoNS Coagulase negative Staphylococci

\subsection{Determination of Antimicrobial Susceptibility Patterns}

The results of the antimicrobial susceptibility pattern were as shown in table 4.1. The isolates were generally susceptible to most of the antibiotics used and they were all $100 \%$ resistant to ampicillin. $E$. coli and Pseudomonas species were additionally $100 \%$ resistance to cefotaxime but were susceptible to all the other antimicrobial agents used. Coagulase negative Staphylococcus and Bacillus species were susceptible to all the antibiotics except for ampicillin. In addition to ampicillin, Proteus species isolates were $100 \%$ resistant to cotrimoxazole, penicillin and cefotaxime but were susceptible to the rest of the antimicrobial agents used in this study (Table 4.1).

Table4.1. Antimicrobial Susceptibility Profiles of the Isolates

\begin{tabular}{|c|c|c|c|c|c|c|c|c|c|c|}
\hline \multirow[t]{2}{*}{$\begin{array}{c}\text { Antimicrobial } \\
\text { Agent }\end{array}$} & \multicolumn{2}{|c|}{ E.coli } & \multicolumn{2}{|c|}{ CoNS } & \multicolumn{2}{|c|}{ Bacillus spp } & \multicolumn{2}{|c|}{$\begin{array}{c}\text { Pseudomonas } \\
\text { spp }\end{array}$} & \multicolumn{2}{|c|}{ Proteus spp } \\
\hline & $\% \mathrm{~S}$ & $\% \mathrm{R}$ & $\% \mathrm{~S}$ & $\% \mathbf{R}$ & $\% \mathrm{~S}$ & $\% \mathbf{R}$ & $\% \mathrm{~S}$ & $\% \mathrm{R}$ & $\% \mathrm{~S}$ & $\% \mathrm{R}$ \\
\hline Amoxicillin & 100 & 0 & 100 & 0 & 86 & 0 & 100 & 0 & 100 & 0 \\
\hline Amikacin & 100 & 0 & 100 & 0 & 100 & 0 & 100 & 0 & 100 & 0 \\
\hline Ampicillin & 0 & 100 & 0 & 100 & 0 & 100 & 0 & 100 & 0 & 100 \\
\hline Cefotaxime & 0 & 100 & 55 & 45 & 86 & 14 & 0 & 100 & 0 & 100 \\
\hline Ciprofloxacin & 100 & 0 & 100 & 0 & 100 & 0 & 100 & 0 & 100 & 0 \\
\hline Cotrimoxazole & 97 & 3 & 100 & 0 & 100 & 0 & 100 & 0 & 0 & 100 \\
\hline Chloramphenicol & 100 & 0 & 97 & 3 & 97 & 3 & 100 & 0 & 100 & 0 \\
\hline Gentamicin & 100 & 0 & 100 & 0 & 100 & 0 & 100 & 0 & 100 & 0 \\
\hline Oxacillin & - & - & 100 & 0 & - & - & - & - & - & - \\
\hline Penicillin & 70 & 30 & 100 & 0 & 100 & 0 & 100 & 0 & 0 & 100 \\
\hline Tetracycline & 100 & 0 & 96 & 4 & 90 & 10 & 100 & 0 & 100 & 0 \\
\hline Vancomycin & - & - & 64 & 38 & - & - & - & - & - & - \\
\hline
\end{tabular}

$\% R=$ Percentage of resistance, $\% S=$ Percentage of sensitivity to the antimicrobial agents. 


\section{DISCUSSION}

Escalators and lifts are used every day by different people as they walk around shopping malls. However, studies have implicated escalator handrails and lift buttons as some of the most bacterial contaminated public surfaces (Ashgar \& El-said 2012; Irshaid et al., 2014; Elsergany et al., 2015). The results of this study demonstrated that all the escalator handrails and lift buttons sampled were contaminated with bacteria. The bacteria found on the escalator handrails and lift buttons were E. coli, coagulase CoNS, Bacillus species, and Proteus species. Our findings demonstrate that Gram-negative bacteria $(61.5 \%)$ were the predominant contaminants of the escalator handrails and lift buttons in shopping malls. The isolation of bacteria as demonstrated by our study shows that these shopping mall surfaces could play an important role in the transmission of microbial agents in the community and thus presents a public health threat. In addition, $E$. coli, CoNS and Bacillus species were isolated in all the shopping malls.

The findings of this study demonstrated that E. coli was the most predominant isolate found to contaminate the escalator handrails and lift buttons. Our findings are consistent with those of a study done in the USA in which E. coli was the most isolated organism at 51\% (Gerba \& Maxwell, 2011). The detection of $E$. coli in our study is an indication of faecal contamination and may be attributed to compromised hygiene practises by the general public, which may include; improper hand washing after using the toilet and after changing of diapers, contact with raw foods, animal faeces, and other contaminated body parts. Although $E$. coli is generally considered as an opportunistic pathogen, studies have shown pathogenic strain O157:H7 on currency (Jiang and Doyle, 1999; Ehwarieme, 2012). Hence, there is the possibility of pathogenic E.coli to be found on escalator handrails and lift buttons.

The coagulase negative Staphylococci were the second predominant isolates on the escalator handrails and lift buttons in most of the shopping malls, an indication of their ubiquitous nature. CoNS have long been regarded as non-pathogenic but their importance as pathogens and their increasing incidence have been recognised and studied in recent years (Akoachere et al., 2014). The isolation of CoNS (23.1\%) in our study was relatively lower compared to a study conducted in Nigeria where $33 \%$ of the isolates were CoNS (Sherifat et al, 2015). The difference may be due to the fact that, the study in Nigeria had a bigger sample size. However, the presence of CoNS in our study can be attributed to the fact that these bacteria are normal flora of the skin, thus expected to be present on surfaces that are frequently touched by humans. In addition, skin-associated bacteria are generally resilient and can survive on surfaces for extended periods of time (Lopez et al., 2013). The other reason for the presence of coagulase negative Staphylococcus on these surfaces can be attributed to the contaminated hands of people who cough and sneeze directly in their hands.

Bacillus species are spore-forming organisms that inhabit the soil and are ubiquitous in the environment (Akoachere et al., 2014). These bacteria were the third common isolates and were detected from all shopping malls. Some studies done to assess the contamination of frequently touched surfaces have isolated Bacillus species and reported that they are some of common contaminants of such surfaces (Ashgar \& El-said, 2012; Yazah et al., 2012). These reports are in line with the findings of our study seeing that Bacillus species were isolated from all sampled shopping malls. The presence of Bacillus species on escalator handrails and lift buttons indicate contamination with soil material. Our data collection was done during the rainy season when most parts of Lusaka are muddy, hence making frequently touched surfaces more prone to contamination with soil materials. Bacillus species are generally perceived to be medically insignificant, but some previous studies have highlighted the relevance of some species of these bacteria as causative agents of nongastrointestinal infections (Rowan et al., 2003).

Pseudomonas species are free living opportunistic pathogens which are responsible for most nosocomial infections. Pseudomonas aeruginosa is responsible for the most infections caused by Pseudomonas (Mujkić et al., 2013). These were the least isolated bacteria and were only detected in one shopping mall. The presence of Pseudomonas species on escalator handrails and lift buttons as shown in our study, may predispose people, especially those with compromised and impaired defence mechanism to opportunistic infections. The other least isolate were Proteus species, like Pseudomonas species, Proteus were isolated from only one shopping mall. Our results are consistent with a study done in Cameroon, where Proteus species were the least isolated bacteria (Akoachere et al., 2014). This bacteria is a members of the Enterobacteriaceae family and it is considered pathogenic. Proteus mirabilis is associated with urinary tract infections (UTIs) (Arunabha et al., 2015). Our results suggest that people who regularly visit shopping malls may be at risk of acquiring bacteria that will predispose them to infections. 
Antimicrobial susceptibility testing demonstrated that all the isolates were susceptible to most of the antibiotics used in this study but were $100 \%$ resistant to ampicillin. These results are similar to a study conducted in Cameroon (Akoachere et al., 2014). E. coli, the most common isolated organism were highly susceptible to amikacin, gentamicin and other antibiotics used in the study but were resistant to ampicillin and cefotaxime. Our findings are consistent with a study done in India in which it was noted that $E$. coli was highly susceptible to amikacin $(85.1 \%$ ) and resistant to ampicillin (97.8\%) (Khan et al., 2014). Amikacin has been reported to be one of the most effective antibiotics against E. coli and Proteus species (Bano et al., 2012; Srikanta et al., 2015). These studies support the results of our study where all the Proteus species and E. coli isolates were sensitive to amikacin. The $30 \%$ resistance of some of the $E$. coli isolates to penicillin are of medical importance, because it is an indication of emerging resistance of these common contaminants to frequently used antibiotic.

Coagulase negative Staphylococcus and Bacillus species isolates were susceptible to most of the antibiotics used in this study except for ampicillin were they showed $100 \%$ resistance. These results are consistent with studies done in some parts of Africa and India (Bano et al., 2012; Akoachere et al., 2014; Khan et al., 2014). A higher percentage CoNS isolates were resistant to Cefotaxicin (45\%) and vancomycin (38\%), these results cannot be overlooked because they indicate a possibility of emerging resistant strains of Staphylococcus which will be difficult to manage in the near future. The isolates Pseudomanas species were resistant to ampicillin and cefotaxime, while the isolates for Proteus were resistant to ampicillin, cefotaxime, cotrimoxazole and penicillin. The resistance of these microorganisms to some of the commonly used antibiotics imply that people who frequently visit these shopping malls might be at risk of being exposed to bacterial infections that would difficult to treat.

These results call for particular attention because these surfaces can be a source of transmission, even of other resistant strains of bacteria not isolated in this study. There is therefore need for the relevant authorities and the general public to ensure that these surfaces are kept clean by disinfecting them and observing good hygiene practices.

\section{CONCLUSION}

All the sampled surfaces were contaminated. Six (6) species of bacteria were isolated, the most common isolate was E. coli, other isolates were, Bacillus species, Coagulase negative Staphylococcus, Proteus species and Pseudomonas species. The majority of these isolates were susceptible to amoxicillin, amikacin, ciprofloxacin, cotrimoxazole, chloramphenicol, gentamicin, penicillin and tetracycline. All the isolates were resistant to ampicillin, E. coli and Pseudomonas species were additionally resistant to cefotaxime and Proteus species were additionally resistant to cefotaxime, cotrimoxazole and gentamicin. These results indicate that escalator handrails and lift buttons are contaminated and may be a source of infection which would be difficult to treat with some commonly used antibiotics. This therefore, is possible health risk to the general public using these facilities.

\section{ACKNOWLEDGEMENT}

The authors wish to acknowledge the department of Biomedical Sciences at The University of Zambia, School of Health Sciences for the technical and material support rendered to this study.

\section{REFERENCES}

[1] Alwakeel, S. S. and Nasser, L. A. (2011). Bacterial and fungal contamination of Saudi Arabian Paper Curency and Cell Phones. Asian Journal of Biological Sciences 4:556-562.

[2] Akoachere J. F., Nana G., Henry M. D. and Theresa K N. (2014). Public health implications of contamination of Franc CFA (XAF) circulating in Buea (Cameroon) with drug resistant pathogens. BMC Research Notes, 7:16.

[3] Arunabha Sarkar, Varsha Rani Gajamer, Hare Krishna Tiwari, Prem Dorjee Bhutia, Sankha Subra Sen, Ranadeep Ghosh. (2015). Detection of antibiotic resistance pattern with ESBL producers and MRSA among the uropathogens at Tertiary Health Care Centre, North Bengal. International Journal of Pure \& Appliied Bioscience, 3:522-533.

[4] Anderson R. M.(1991). Infectious diseases of humans, dynamics and control, Oxford University press. New York.

[5] Ashgar, S. S., \& El-said, H. M. (2012). Pathogenic Bacteria Associated with Different Public Environmental Sites in Mecca City. Open Journal of Medical Microbiology, 2:133-137.

[6] Bano, I., Chaudhary, W.A. \& Hameed, A., 2012. In vitro bacteriologic study and empiric antibiotic regimens for diabetic foot ulcers. African Journal of Microbiology Research, 6:5568-5573. 
Bacteriological Analysis of Escalator Handrails and Lift Buttons of Selected Shopping Malls in Lusaka Zambia: The Public Health Risk Implication

[7] Brady, R. R. W., Verran, J., Damani, N. N., \& Gibb, A. P. (2009). Review of mobile communication devices as potential reservoirs of nosocomial pathogens. Journal of Hospital Infection, 71:295-300.

[8] Dictionary of architecture. Journal of the Franklin Institute (Vol. 254).

[9] Ehywarieme, D.A., 2012. R-Plasmids Amongst E Coli O157:H7 Isolated from Nigerian Currency Notes. International Journal of Tropical Medicine and Public Health, 1:17-22

[10]Elsergany, M., Moussa, M., AHSAN, A., Khalfan, A., \& Eissa, A. (2015). Exploratory Study of Bacterial Contamination of Different Surfaces in Four Shopping Malls in Sharjah, UAE. Journal of Environmental and Occupational Science, 4:101-105.

[11]Flores, G. E., Bates, S. T., Knights, D., Lauber, C. L., Stombaugh, J., Knight, R., \& Fierer, N. (2011). Microbial Biogeography of Public Restroom Surfaces. PLOS ONE, 6: e28132.

[12] Gerba, C. P., \& Maxwell, S. (2012). Bacterial contamination of shopping carts and approaches to control. Food Protection Trends 32:747-749.

[13] Goldman, S. (2012). Assement of Gram-positive Bacterial Contamination on Supermarket Shopping Baskets and Trollys in Khartoum City, Sudan. 1-30.

[14] Irshaid, F. I., Jacob, J. H., \& Khwaldh, A. S. (2014). Contamination of the Handles and Bases of Shopping Carts By Pathogenic and Multi-Drug Resistant Bacteria. European Scientific Journal, 10:1857 - 7881.

[15] Jiang X, Doyle MP (1999) Fate of Escherichia coli O157:H7 and Salmonella enteritidis on currency. J Food Protect, 62:805-807.

[16] Kharn, U.I,. Ali, M. and Afzal, A. (2014). Antimicrobial susceptibility pattern of bacterial isolated from patients with urine tract infection. Journal of the college of physicians, 24:840-844.

[17]Lopez, G. U., Gerba, C. P., Tamimi, A. H., Kitajima, M., Maxwell, S. L., \& Rose, J. B. (2013). Transfer efficiency of bacteria and viruses from porous and nonporous fomites to fingers under different relative humidity conditions. Applied and Environmental Microbiology, 79:5728-5734.

[18] Mkrtchyan, H. V, Russell, C. A., Wang, N., \& Cutler, R. R. (2013). Could Public Restrooms Be an Environment for Bacterial Resistomes? PLoS ONE, 8:e54223.

[19] Mujkić, A.J., Bešta, R. \& Memišević, S., 2013. Bacterial contamination of public telephones in the downtown area of Sarajevo. African Journal of Microbiology Research, 7:1664-1667.

[20] Neel, R. (2013). (MRSA). In Paper Currency Notes from Restaurants and Hotels in Lusaka in Zambia. International Journal of Pharmacy and Pharmaceutical Sciences, 5:363-366.

[21] Neel, R. (2012). Isolation of Pathogenic Microorganisms from Different Market Places in Korogwe and Mombo Towns in Tanzania. Journal of Microbiology and Biotechnology Research 2:470-474.

[22] Rowan, J. Neil, Caldow George, Gemmell G. Curtis and Hunter S. Iain. (2003). Production of Diarrheal Enterotoxins and Other Potential Virulence Factors by Veterinary Isolates of Bacillus Species Associated with Nongastrointestinal Infections. Applied and Environmental Microbiology, 69:2372-2376.

[23] Sherifat T., Oloruntobi A, Oluwabiyi, Bolatito A., Abimbola, Wunmi A. (2015) Bacterial Contamination of Handrails of A Major Market in Ijebu-Ode. Acta Velit, 1:95-99.

[24] Srikanta, C. and Ramendu, P. (2015). Antibiotic Susceptibility Patterns of Bacterial among Urinary Tract Infection patients in Chittagong. Sikkim Manipal University Medical Journal, 2:114-126

[25] Wilks, S. A., Michels, H. T., \& Keevil, C. W. (2006). Survival of Listeria monocytogenes Scott A on metal surfaces : Implications for cross-contamination. International Journal of Food Microbiology, 111:93-98.

Citation: Sydney Malama, et.al (2020). “Bacteriological Analysis of Escalator Handrails and Lift Buttons of Selected Shopping Malls in Lusaka Zambia: The Public Health Risk Implication". International Journal of Research Studies in Microbiology and Biotechnology (IJRSMB), vol. 6, no. 2, pp. 22-27, 2020. Available: DOI: https:// doi.org/ 10.20431/2454-9428.0602005

Copyright: () 2020 Authors. This is an open-access article distributed under the terms of the Creative Commons Attribution License, which permits unrestricted use, distribution, and reproduction in any medium, provided the original author and source are credited. 